\title{
FAKTOR-FAKTOR YANG MEMPENGARUHI PERGAULAN BEBAS PADA REMAJA DI SMK SWASTA JAYA KRAMA BERINGIN KECAMATAN BERINGIN KABUPATEN DELI SERDANG
}

\author{
Rosita Ginting ${ }^{1}$, Desideria Yosepha Ginting ${ }^{2}$, Irmayani ${ }^{3}$ \\ Institut Kesehatan Medistra Lubuk Pakam \\ Jl. Sudirman No.38 Lubuk Pakam Kec. Lubuk Pakam Kab. Deli Serdang, \\ Sumatera Utara \\ Email: rositaginting25@gmail.com \\ DOI : https://doi.org/10.35451/jkg.v2i2.400
}

\begin{abstract}
The emergence of promiscuity among young people who are rife lately is inseparable from the influence of the globalization era which is considered a form of modernity for some adolescents, which ultimately brings them closer to promiscuity who are at risk of being infected with various kinds of socially transmitted diseases. which affects promiscuity in adolescents in the Jaya Krama Beringin Private Vocational School Sidodadi Village, Beringin District, Deli Serdang Regency. The research method used was analytic survey, with cross sectional approach. The sampling technique used was purposive sampling. Samples are taken based on specified criteria. Data analysis was performed bivariately with chi-square test with a value of a (0.05). The results showed that social factors and technological factors / mass media are factors that influence the incidence of free association in adolescents in the Jaya Krama Beringin Private Vocational School with each value of $p=0.02<a=$ 0.05 and $p$ value $=0.002<a=0.05$. The importance of improving education, coaching and monitoring students in the use of technology to students so as to avoid promiscuity.
\end{abstract}

\section{Keywords: Adolescent, free sex}

\section{Pendahuluan}

Masa remaja merupakan masa transisi yang kritis sebagai kunci berkembangnya pengalaman baru yaitu usia 10-19. Masa remaja dihadapkan pada dorongan untuk mengkonsumsi alkohol, rokok, atau obat-obatan lain serta memulai perilaku pergaulanual. Hal ini menjadikan resiko terjadinya kehamilan yang tidak diinginkan, infeksi menular pergaulanual (IMS) termasuk HIV serta masalah penyesuaian dengan kesehatan mental (Sumiati, 2017).

Penelitian dibeberapa negara berkembang menunjukkan $40 \%$ remaja pria dan remaja putri umur 8 tahun telah melakukan hubungan pergaulan meskipun tanpa ada ikatan pernikahan. Akibat dari hubungan pergaulanual pranikah, sekitar $12 \%$ telah terkena positif Penyakit Menular Seksual, sekitar $27 \%$ positif HIV, dan $30 \%$ remaja putrid telah hamil, setengah dari mereka melahirkan namun setengahnya lagi melakukan aborsi (Mangondo, 2014).

Permasalahan seks remaja salah satunya adalah seks pranikah. Centers For Disease Control And Prevention merilis pada hasil survey menunjukkan bahwa remaja di Amerika Serikat tahun 2015, 41\% pernah melakukan hubungan seksual, $30 \%$ pernah 
melakukan hubungan seksuall pada 3 bulan sebelumnya, $21 \%$ konsumsi alkohol atau obat-obatan dan digunakan sebelum melakukan hubungan seksual terakhir.

Kedaruratan pergaulan remaja terkait seks pranikah dapat diketahui melalui laporan Dinas Kesehatan DIY. Pada tahun 2015 terdapat 1.078 remaja usia sekolah di DIY menjalani persalinan, 976 diantaranya hamil di luar pernikahan. Pergaulan remaja yang cenderung bebas atau kurang baik menjadi salah satu penyebab kehamilan di luar nikah di kalangan remaja (Sari, 2016).

Hasil studi pendahuluan ditemukan sebanyak 365 siswa/siswi SMK pada kelas $X$ yang berjumlah 178 dan kelas XI yang berjumlah 187 . Berdasarkan hasil dari wawancara siswa/siswi yang berada disekolah terdapat beberapa perilaku menyimpang yang dilakukan para remaja tersebut, salah satu contonhnya ada beberapa remaja yang berpacaran ke arah yang negatif dan bahkan itu hal yang wajar bagi mereka. Perilaku remaja tersebut merupakan perilaku yang menyimpang terhadap normanorma yang berlaku dimasyarakat. Berdasarkan penjelasan diatas peneliti tertarik untuk melakukan penelitian secara mendalam tentang pergaulan bebas dan faktor-faktor yang mempengaruhi terjadinya pergaulan bebas pada remaja di SMK Swasta Jaya Krama Beringin Kec. Beringin Kab. Deli Serdang.

\section{METODE PENELITIAN}

Jenis penelitian yang digunakan pada penelitian ini yaitu penelitian kuantitatif dengan pendekatan survey analitik, menggunakan desain penelitian yaitu cross sectional yang bertujuan untuk menjelaskan faktor-faktor yang mempengaruhi pergaulan bebas pada remaja di SMK Swasta Jaya Krama
Beringin Kecamatan Beringin Kabupaten Deli Serdang yang diukur dan dikumpulkan pada waktu yang bersamaan dan dilakukan pada situasi saat yang sama (Sugiyono, 2018). Populasi dalam penelitian ini seluruh seluruh siswa di SMK Swasta Jaya Krama Beringin Kecamatan Beringin Kabupaten Deli Serdang sebanyak 365 orang. Pengambilan sampel dengan menggunakan tekhnik purposive sampling. Pengumpulan data dengan menggunakan data primer dan data sekunder. Wawancara kepada responden dengan berpedoman pada kuesioner yang telah dipersiapkan merupakan teknik yang digunakan dalam mengumpulkan data primer. Sedangkan data sekunder diperoleh dari bagian tata usaha di SMK Swasta Jaya Krama Beringin Kecamatan Beringin Kabupaten Deli Serdang. Setelah data terkumpul. Kemudian diolah dengan menggunakan uji chi square dengan tingkat kepercayaan 95\% (alpha $=5 \%)$. Dasar pengambilan keputusan dengan ketentuan jika nilai $\mathrm{p}<\mathrm{a}$ maka Ho ditolak yang dapat disimpulkan bahwa terdapat hubungan antara variabel independent dengan dependent.

3. HASIL

Tabel 1. Distribusi Responden Berdasarkan Faktor Pergaulan

\begin{tabular}{llr}
\hline \multicolumn{1}{c}{ Pergaulan } & \multicolumn{1}{c}{ f } \\
\hline Baik & 19 & 47,5 \\
Buruk & 21 & 52,5 \\
\hline \multicolumn{1}{c}{ Total } & $\mathbf{4 0}$ & $\mathbf{1 0 0 , 0}$ \\
\hline
\end{tabular}

Tabel 1 menunjukkan bahwa sebagian besar remaja memilik pergaulan buruk sebanyak $52,5 \%$.

Tabel 2 Distribusi Responden Berdasarakan Teknologi/ Media Massa Teknologi/ f $\quad \%$ Media Massa 
Received: 15 April 2020 :: Accepted: 26 April 2020 :: Published: 30 April 2020

\begin{tabular}{lrr}
\hline $\begin{array}{l}\text { Baik } \\
\text { Buruk }\end{array}$ & 15 & 37,5 \\
& 25 & 62,5 \\
\hline \multicolumn{1}{c}{ Total } & $\mathbf{4 0}$ & $\mathbf{1 0 0 , 0}$ \\
\hline
\end{tabular}

Tabel 2 menunjukkan bahwa mayoritas faktor teknologi/ media massa berada pada kategori buruk sebesar $62,5 \%$.

Tabel 3. Distribusi Responden Berdasarakan Faktor Lingkungan Masyarakat

\begin{tabular}{llr}
\hline $\begin{array}{l}\text { Lingkungan } \\
\text { Masyarakat }\end{array}$ & \multicolumn{1}{c}{ F } & \multicolumn{1}{c}{$\%$} \\
\hline Baik & 17 & 42,5 \\
Buruk & 23 & 57,5 \\
\hline \multicolumn{1}{c}{ Total } & $\mathbf{4 0}$ & $\mathbf{1 0 0 , 0}$ \\
\hline
\end{tabular}

Dari tabel 3 dapat diketahui bahwa sebagian besar responden berada pada lingkungan masyarakat yang buruk yaitu sebesar $57,5 \%$.

Tabel 4 Pengaruh Pergaulan terhadap Kejadian Pergaulan Bebas

\begin{tabular}{|c|c|c|c|c|}
\hline \multirow{3}{*}{$\begin{array}{c}\text { Perga } \\
\text { ulan }\end{array}$} & \multicolumn{2}{|c|}{$\begin{array}{c}\text { Pergaulan } \\
\text { Bebas }\end{array}$} & \multirow{3}{*}{$\begin{array}{c}\text { Total } \\
\text { n }\end{array}$} & \multirow[t]{3}{*}{$\begin{array}{l}\text { Nilai } \\
\text { p }\end{array}$} \\
\hline & Ya & Tidak & & \\
\hline & $n$ & $\mathbf{n}$ & & \\
\hline Baik & 5 & 14 & 19 & 0,02 \\
\hline Buruk & 13 & 8 & 21 & \\
\hline Total & 18 & 22 & 40 & \\
\hline
\end{tabular}
terdapat pengaruh yang signifikan pergaulan terhadap kejadian pergaulan bebas $(p=0,02)<(a=0,05)$.

Tabel 5 Pengaruh Teknologi/ Media Massa terhadap Kejadian Pergaulan Bebas

\begin{tabular}{|c|c|c|c|c|}
\hline \multirow{2}{*}{$\begin{array}{c}\text { Teknolo } \\
\text { gi Media } \\
\text { Massa }\end{array}$} & \multicolumn{2}{|c|}{$\begin{array}{c}\text { Pergaulan } \\
\text { Bebas }\end{array}$} & \multirow{2}{*}{$\begin{array}{c}\text { Total } \\
\text { n }\end{array}$} & \multirow[t]{2}{*}{$\begin{array}{c}\text { Nilai } \\
\mathbf{p}\end{array}$} \\
\hline & Ya & $\begin{array}{c}\text { Tidak } \\
n\end{array}$ & & \\
\hline Baik & 2 & 13 & 19 & 0,00 \\
\hline Buruk & 16 & 9 & 21 & 2 \\
\hline Total & 18 & 22 & 40 & \\
\hline
\end{tabular}

Tabel 5 menunjukkan bahwa terdapat pengaruh yang signifikan teknologi/ media massa terhadap kejadian pergaulan bebas $(p=0,002)<$ $(a=0,05)$.

Tabel 6 Pengaruh Lingkungan Masyarakat terhadap Kejadian Pergaulan Bebas

\begin{tabular}{|c|c|c|c|c|}
\hline \multirow{3}{*}{$\begin{array}{l}\text { Lingkun } \\
\text { gan } \\
\text { Masyara } \\
\text { kat }\end{array}$} & \multicolumn{2}{|c|}{$\begin{array}{c}\text { Pergaulan } \\
\text { Bebas }\end{array}$} & \multirow{3}{*}{$\begin{array}{c}\text { Total } \\
\text { n }\end{array}$} & \multirow[t]{3}{*}{$\begin{array}{l}\text { Nilai } \\
\text { p }\end{array}$} \\
\hline & Ya & Tidak & & \\
\hline & $\mathbf{n}$ & $\mathbf{n}$ & & \\
\hline Baik & 8 & 9 & 17 & 0,82 \\
\hline Buruk & 10 & 13 & 23 & \\
\hline Total & 18 & 22 & 40 & \\
\hline
\end{tabular}
tidak terdapat pengaruh yang signifikan lingkungan masyarakat terhadap kejadian pergaulan bebas $(p=0,82)<$ $(a=0,05)$.

\section{PEMBAHASAN}

Tabel 4 menunjukkan bahwa ada pengaruh faktor pergaulan dengan terjadinya Pergaulan Bebas Pada Remaja di SMK Swasta Jaya Krama Beringin. Hal ini sejalan dengan dengan penelitian yang dilakukan oleh Ihsan (2016) pola pergaulan berpengaruh signifikan terhadap remaja dan pembentukan karakte rremaja. Konsep pergaulan merupakan interaksi antar individu dalam mengenal lingkungan sosialnya. Konsep pergaulan pada hakikatnya merupakan jalinan hubungan sosial antara seseorang dengan orang lain yang berlangsung dalam jangka relative lama sehingga terjadi saling mempengaruhi satu dengan lainnya.

Pergaulan

merupakan kelanjutan dari proses hubungan sosial yang terjalin antara individu dalam lingkungan sosialnya. Kuat lemahnya suatu interaksi sosial mempengaruhi erat tidaknya pergaulan yang terjalin. Seorang anak yang selalu bertemu dan berinteraksi dengan orang lain dalam jangka waktu relative lama akan membentu kpergaulan yang lebih. 
Berbeda dengan orang yang hanya sesekali bertemu atau hanya melakukan interaksi social secara tidak langsung (Mustakim, 2018).

Berdasarkan asumsi peneliti yaitu, mengapa ada pengaruh antara faktor pergaulan dengan pergaulan bebas pada remaja yaitu karena pergaulan mempunyai pengaruh yang cukup besar dalam pembentukan kepribadian remaja. Pergaulan yang dilakukannya akan mencerminkan kepribadiannya, baik pergaulan yang positif maupun pergaulan yang negatif.

Tabel 5 menunjukkan bahwa ada pengaruh faktor teknologi/media massa dengan terjadinya pergaulan Bebas Pada Remaja di SMK Swasta Jaya Krama Beringin.

Hal ini sejalan dengan dengan penelitian yang dilakukan oleh Mustakim (2018) bahwa media massa sangat berpengaruh terhadap pergaulan bebas pada remaja. Aktivitas seksual remaja banyak dipengaruhi kemajuan teknologi, seperti media cetak dan elektronik. Remaja mudah memperoleh hal-hal berbau pornografi dari majalah, televise, VCD dan internet, sedangkan remaja cenderung untuk meniru atau mencoba-coba hal yang baru demi menjawab rasa penasaran mereka.

Telepon genggam (handphone) seolah-olah menjadi kebutuhan mendasar bagi semua orang untuk melakukan koneksi komunikasi jarak jauh, dibandingkan dengan surat pos atau telegram yang memerlukan waktu jauh lebih lama dibandingkan telepon genggam. Tidak hanya itu, teknologi juga memungkinkan industri media untuk memproduksi media yang lebih beragam, setidaknya kondisi ini dapat dilihat bahwa media tidak hanya berada dalam bentuk cetak semata, tetapi masyarakat juga dapat menemukan media yang hampir sama dalam bentuk elektronik (Jamaludin, 2016).
Media massa sudah menjadi suatu kebutuhan sehari-hari bagi sebagian masyarakat dunia, termasuk anak-anak dan remaja. Di Indonesia internet menjadi media favorit bagi penyebar konten pornografi, bahkan transaksi perdagangan terbesar negeri kita melalui internet diperolah dari bisnis pornografi. Cukup miris jika dibayangkan, karena dengan internet setiap orang dapat berselancar bebas untuk menjalankan aplikasi multimedia. Dan penelitian ini membuktikan bahwa terapan media massa berpengaruh signifikan terhadap pergaulan bebas dan pembentukan karakter remaja pada pergaulan bebas (Ihsan, 2016).

Berdasarkan asumsi peneliti yaitu, adanya pengaruh antara faktor teknologi/media massa dengan pergaulan bebas pada remaja yaitu karena pesatnya perkembangan teknologi/media massa merupakan penyebab pergaulan bebas yang memiliki pengaruh yang sangat besar. Pengaruh media massa contonya handphone dan internet sering kali di salahgunakan oleh kaum remaja dalam perilaku sehari-hari. Remaja akan cenderung mencoba dan meniru apa yang ditontonya.

Tabel 6 menunjukkan bahwa tidak ada pengaruh faktor lingkungan masyarakat dengan terjadinya Pergaulan Bebas Pada Remaja di SMK Swasta Jaya Krama Beringin.

Hal ini sejalan dengan penelitian sebelumnya menunjukkan tidak adanya pengaruh antara lingkungan dengan remaja. Remaja yang melakukan seks bebas atau pergaulan bebas yang cukup tinggi, justru memiliki lingkungan tempat tinggal yang tidak beresiko. Hal ini dapat disebabkan karena remaja lebih memilih tempat tinggal sendiri untuk melakukan perilaku seks pranikah atau pergaulan remaja. 
Received: 15 April 2020 :: Accepted: 26 April 2020 :: Published: 30 April 2020

Berdasarkan asumsi peneliti, alasan mengapa tidak ada pengaruh antara faktor lingkungan dengan terjadinya pergaulan pergaulan bebas pada remaja adalah karena lingkungan masyarakata yang berada disekitar responden terdapat lingkungan yang baik, dan masyarakat dilingkungan responden cenderung berpartisipasi dalam pelaksaan gotong royong, dan senantiasa mencontohkan perbuatan yang baik pada lingkungannya.

\section{KESIMPULAN}

Kesimpulan pada penelitian ini yaitu ada pengaruh pergaulan dan teknologi/ media massa terhadap kejadian pergaulan bebas dan tidak pengaruh lingkungan masyarakat terhadap kejadian pergaulan bebas.

\section{DAFTAR PUSTAKA}

Ihsan, M. (2016). Pengaruh Terapan Media Internet dan Pola Pergaulan Terhadap Karakter Peserta Didik. Tsamrah al-fikri Vol. 10, 2016 , 103-119.

Jamaludin, A. N. (2016). Dasar-dasar Patologi Sosial. Bandung: CV Pustaka Setia.

Mangondo. (2014). Hubungan Antara Pengetahuan dan Sikap Remaja dengan Tindakan Seks Pranikah Pada Siswa Kelas XI di SMK Negeri 2 Manado. Jurnal Kedokteran Komunitas dan Tropik. Vol. II. No. 1. Februari 2014.

Mustakim, H. (2018). Faktor-faktor yang Berhubungan dengan Perilaku Seks Pranikah Mahasiswi Akademi Kebidanan Sinar Kasih Toraja Tahun 2016. Jurnal Ilmiah Kesehatan Volume 12 Nomor 5 Tahun 2018 , 574581.

Sari. (2016). Faktor-faktor yang Berhubungan dengan Kejadian Unitended Pregnancy Pada Remaja. Jurnal Kebidanan dan Keperawatan 12 (2), 163-172.
Sugiyono. (2018). Metode Penelitian Kuantitatif, Kualitatif, dan R\&D. Bandung: ALFABETA.

Sumiati. (2017). Kesehatan Jiwa Remaja dan Konseling. Jakarta: TIM. 